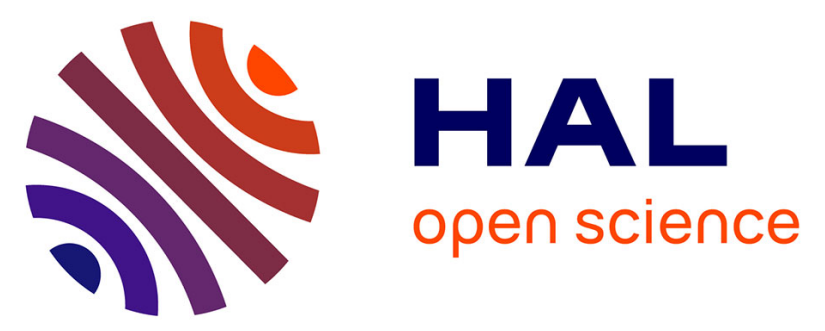

\title{
Influence of preparation procedure on catalytic activity of PdBEA zeolites in aqueous phase hydrodechlorination of 1,1,2-trichloroethene
}

Izabela I. Kamińska, Dmytro Lisovytskiy, Sandra Casale, Anna Śrębowata, Stanislaw Dzwigaj

\section{To cite this version:}

Izabela I. Kamińska, Dmytro Lisovytskiy, Sandra Casale, Anna Śrębowata, Stanislaw Dzwigaj. Influence of preparation procedure on catalytic activity of PdBEA zeolites in aqueous phase hydrodechlorination of 1,1,2-trichloroethene. Microporous and Mesoporous Materials, 2017, 237, pp.6573. 10.1016/j.micromeso.2016.09.023 . hal-01375430

\section{HAL Id: hal-01375430 \\ https://hal.sorbonne-universite.fr/hal-01375430}

Submitted on 3 Oct 2016

HAL is a multi-disciplinary open access archive for the deposit and dissemination of scientific research documents, whether they are published or not. The documents may come from teaching and research institutions in France or abroad, or from public or private research centers.
L'archive ouverte pluridisciplinaire HAL, est destinée au dépôt et à la diffusion de documents scientifiques de niveau recherche, publiés ou non, émanant des établissements d'enseignement et de recherche français ou étrangers, des laboratoires publics ou privés. 
Influence of preparation procedure on catalytic activity of PdBEA zeolites in aqueous phase hydrodechlorination of 1,1,2-trichloroethene

Izabela I. Kamińska ${ }^{a}{ }^{*}$, Dmytro Lisovytskiy ${ }^{\mathrm{a}}$, Sandra Casale ${ }^{\mathrm{b}}$, Anna Śrębowata ${ }^{\mathrm{a}}$, Stanislaw Dzwigaj, ${ }^{\mathrm{b}, *}$

anstitute of Physical Chemistry, PAS, Kasprzaka 44/52, PL-01224 Warsaw, Poland ${ }^{\mathrm{b}}$ Sorbonne Universités, UPMC Univ Paris 06, CNRS, UMR 7197, Laboratoire de Réactivité de Surface, 4 place Jussieu, Case 178, 75252 Paris, France

Figures: 10

Tables: 3

Keywords: Pd, BEA, 1,1,2-trichloroethene, aqueous-phase hydrodechlorination

*Corresponding authors:

Izabela I. Kamińska, e-mail: iikaminska@ichf.edu.pl, ～tel.: +48 1223433360

Stanislaw Dzwigaj, e-mail: stanislaw.dzwigaj@upmc.fr, tel.: +331442721 13 


\begin{abstract}
Pd-loaded BEA zeolites containing 1 wt $\%$ of Pd were prepared by a two-step postsynthesis method (PdSiBEA and PdSiAlBEA) and a conventional wet impregnation (PdHAlBEA). Modification of BEA zeolite resulted in the introduction of Pd ions into zeolite framework as pseudo-tetrahedral Pd(II) and extra-framework octahedral Pd(II) evidenced by XRD, DR UVvis and TPR measurements. Calcination of as prepared zeolites in air at $773 \mathrm{~K}$ for $3 \mathrm{~h}$ and then reduction in $10 \% \mathrm{H}_{2} / \mathrm{Ar}$ flow at $873 \mathrm{~K}$ for $3 \mathrm{~h}$ led to obtain red-C-PdSiBEA, red-CPdSiAlBEA and red-C-PdHAlBEA zeolites with different Pd nanoparticles size distributions showed by TEM. These zeolite materials were found to be active catalysts in aqueous-phase hydrodechlorination of 1,1,2-trichloroethene (TCE). The conducted catalytic reactions have demonstrated that the rate and course of TCE hydrodechlorination depend on the catalysts preparation method and Pd nanoparticles size.
\end{abstract}




\section{Introduction}

Palladium as noble metal has a wide application in catalytic reactions. It accelerates many hydrogenation and dehydrogenation reactions due to its excellent properties [1-4]. Palladium is also the most extensively used metal in purification of air and water containing toxic substances such as volatile organic compounds (VOCs) [5, 6]. Particular attention should be focused on the removal of chlorinated hydrocarbons like 1,2-dichloroethane (DCA), 1,1,2-trichloroethene (TCE) and 1,1,2,2-tetrachloroethene (PCE), because of their potential carcinogenic and mutagenic effects on living organisms [7-9]. The application of Pd in the hydrodechlorination (HDC) processes allows to easily, cheaply and without damage of environment transforming harmful chemicals into less toxic products like ethane or ethene [10-12].

High hydrodechlorination efficiency of Pd could be affected by a number of factors such as the metallic nanoparticle size, its shape, oxidation state and interaction with the support, among others $[13,14]$. A number of authors have deduced that Pd nanoparticle size is crucial for the performance of HDC reactions [15-20]. One of their hypothesis is that bigger Pd nanoparticles are more active and resistant for reaction conditions [15-17]. However, the others have proved the superiority of small nanoparticles, because of its higher surface-tovolume ratio [18-20]. One of the first reports pertains to research carried out by Juszczyk et al. [15]. They noticed that catalytic activity of $\mathrm{Pd} / \gamma-\mathrm{Al}_{2} \mathrm{O}_{3}$ in gas-phase hydrodechlorination of $\mathrm{CCl}_{2} \mathrm{~F}_{2}$ was strongly related to $\mathrm{Pd}$ dispersion: the samples with the lowest metal dispersion exhibited the highest turnover frequencies. Aramendía et al. [16] observed similar effect in liquid-phase hydrodechlorination of chlorobenzene over Pd-supported catalysts. In this case, the change of dispersion from 54 to $7 \%$ corresponded to an increase in catalytic activity by a factor of 20. In addition, they noticed a better resistance to chlorine, when the size of Pd nanoparticles increased. 
On the other hand, several authors present a different view [18-20]. Gómez-Quero et al. [18] analyzed the effect of metal dispersion on the liquid-phase hydrodechlorination of 2,4dichlorophenol over $\mathrm{Pd} / \mathrm{Al}_{2} \mathrm{O}_{3}$. They observed a significant decrease in reaction rate with a decrease in palladium dispersion from $67 \%$ to $25 \%$, with only residual activity in case of the catalyst with $8 \%$ dispersion. Dong et al. [19] also reported that magnetic porous carbon composite supported palladium nanoparticles $(5 \mathrm{~nm})$ displayed high efficiency in HDC of chlorophenols.

Moreover, the appropriate support has also a significant influence on catalytic activity and stability of Pd catalysts [17]. The most popular Pd supports are activated carbons, silica, titania and alumina [15-19, 21]. Recently, the significant surge of interest in zeolite materials has been observed due to their specific properties (cation exchange, shape selectivity and acidity) [20,22,23]. Śrębowata et al. [20] have found a beneficial effect of desilication of HZSM-5 zeolite on PdHZSM-5 activity in aqueous-phase hydrodechlorination of TCE. It seems to us to be very interesting to investigate the influence of dealumination process on the activity of Pd-loaded zeolites in TCE removal from water. Therefore, we decided to synthetize Pd-loaded BEA zeolites with different dealumination stage and checked their properties by characterization using different techniques and investigated catalytic reaction with TCE in aqueous-phase.

Very interesting results obtained for transition metals-loaded BEA zeolites used in gas-phase HDC [24-27] were the motivation to investigate the effect of preparation procedure on the catalytic properties of Pd-loaded BEA zeolites in aqueous phase hydrodechlorination of 1,1,2-trichloroethene.

\section{Experimental}

\subsection{Catalysts preparation}


TEABEA zeolite $(\mathrm{Si} / \mathrm{Al}=19)$ provided by RIPP (China) was divided into three portions. First portion was treated by a $13 \mathrm{~mol} \mathrm{~L}^{-1} \mathrm{HNO}_{3}$ solution for $4 \mathrm{~h}$ at $343 \mathrm{~K}$ to obtain completely dealuminated $\mathrm{SiBEA}$ zeolite $(\mathrm{Si} / \mathrm{Al}=1300)$. Second portion was treated by a 13 mol L ${ }^{-1} \mathrm{HNO}_{3}$ solution for $3.5 \mathrm{~h}$ at $343 \mathrm{~K}$ to obtain partially dealuminated SiAlBEA zeolite $(\mathrm{Si} / \mathrm{Al}=940)$. The resulting zeolites with vacant T-sites were recovered by centrifugation, washed with distilled water and dried overnight at $353 \mathrm{~K}$. Third portion of TEABEA was calcined in air at $823 \mathrm{~K}$ for $15 \mathrm{~h}$ under static conditions to remove organic template, then treated two times with $0.1 \mathrm{~mol} \mathrm{~L}^{-1} \mathrm{NH}_{4} \mathrm{NO}_{3}$ solution $(400 \mathrm{~mL})$ during $3 \mathrm{~h}$ at $343 \mathrm{~K}$. Resulted $\mathrm{NH}_{4}$ AlBEA was washed with distilled water and dried overnight at $363 \mathrm{~K}$ and next calcined in air at $773 \mathrm{~K}$ for $3 \mathrm{~h}$ under static conditions to remove $\mathrm{NH}_{3}$ and obtain HAlBEA zeolite $(\mathrm{Si} / \mathrm{Al}=17)$.

Palladium-loaded BEA zeolites were prepared by impregnation of SiBEA, SiAlBEA and HAlBEA under ambient conditions by a $9.4 \times 10^{-4}$ mol dm${ }^{-3}$ aqueous solution of $\mathrm{PdCl}_{2}$ ( $\mathrm{pH}$ in the range of $3.0-3.4)$. First, $2 \mathrm{~g}$ of each zeolite materials were stirred at room temperature for $24 \mathrm{~h}$ in excess solvent using $200 \mathrm{ml}$ of the palladium chloride solution ( $\mathrm{pH}$ in the range of $2.9-3.3$ ) and then the suspensions were stirred in a rotary vacuum evaporator at $333 \mathrm{~K}$ for $2 \mathrm{~h}$ until complete evaporation of water. The resulting light-brown solids containing 1 wt $\%$ of Pd were labelled as PdSiBEA, PdSiAlBEA and PdHAlBEA. Next, all these materials were calcined in air flow at $773 \mathrm{~K}$ for $3 \mathrm{~h}$ and labeled C-PdSiBEA, C-PdSiAlBEA and C-PdHAlBEA, respectively. Then, small portions of these materials were reduced at 873 $\mathrm{K}$ for $3 \mathrm{~h}$ in $10 \% \mathrm{H}_{2} / \mathrm{Ar}$ flow to obtain red-C-PdSiBEA, red-C-PdSiAlBEA and red-CPdHAlBEA.

\subsection{Catalysts characterization and catalytic tests}

\subsubsection{Diffuse Reflectance UV-vis Spectroscopy}


Diffuse Reflectance (DR) UV-vis spectra of as prepared samples were recorded at ambient atmosphere on a Cary 5000 Varian spectrometer (DR UV-Vis scan rate $10 \mathrm{~nm} \mathrm{~s}^{-1}$, data interval $1 \mathrm{~nm}$ ) equipped with a double integrator with polytetrafluoroethylene as reference.

\subsubsection{Physisorption}

Surface areas and porosities of calcined samples were measured with an ASAP 2020 instrument from Micromeritics, employing the BET (Brunauer-Emmett-Teller) and HK (Horwath-Kawazoe) methods using nitrogen as adsorbate. Before measuring the adsorption isotherm at $77 \mathrm{~K}$, the samples were kept at $473 \mathrm{~K}$ for $4 \mathrm{~h}$ in vacuum remove adsorbed water and gases.

\subsubsection{Temperature-Programmed Reduction}

Temperature-Programmed Reduction (TPR) of calcined samples was carried out using glass flow system equipped with a Gow-Mac thermal conductivity detector. TPR runs were performed in $10 \% \mathrm{H}_{2} / \mathrm{Ar}$ flow $\left(25 \mathrm{~cm}^{3} \mathrm{~min}^{-1}\right)$, ramping the temperature at $10 \mathrm{~K} \mathrm{~min}^{-1}$, started from $260 \mathrm{~K}$ to $973 \mathrm{~K}$. Injections of known amounts of hydrogen into the $\mathrm{H}_{2} / \mathrm{Ar}$ flow were provided for calibration (before and after each TPR run).

\subsubsection{Chemisorption}

Chemisorption measurements of $\mathrm{CO}$ using a conventional static method were carried out with an ASAP 2020 Chem. instrument from Micromeritics. Prior to chemisorption measurement $0.1 \mathrm{~g}$ of calcined Pd-loaded BEA zeolite was reduced in $10 \% \mathrm{H}_{2} / \mathrm{Ar}$ flow (25 $\mathrm{cm}^{3} \mathrm{~min}^{-1}$ ), ramping the temperature from room to $873 \mathrm{~K}$ (at $10 \mathrm{~K} \mathrm{~min}^{-1}$ ) and kept at $873 \mathrm{~K}$ for $3 \mathrm{~h}$. Then the catalysts were cooled down to the room temperature and connected with the ASAP 2020 Chem. instrument. Chemisorption measurements were carried out according to the procedure described previously [24].

\subsubsection{TCE hydrodechlorination}


Hydrodechlorination of TCE in aqueous-phase were performed in a $500 \mathrm{~mL}$ round bottomed flask equipped with a pH-meter, magnetic stirring bar and temperature controller, using $350 \mathrm{~mL}$ of MiliPore water and $20 \mu \mathrm{L}$ of TCE and $0.1 \mathrm{~g}$ of reduced catalyst (at $873 \mathrm{~K}$ for $3 \mathrm{~h}$ in $10 \% \mathrm{H}_{2} / \mathrm{Ar}$ flow). Each reaction was carried out at $303 \mathrm{~K}$ with continuous stirring (1000 rpm). Before adding the substrate, the water had been saturated with hydrogen for 30 min and then the catalyst was added to reaction mixture. Reaction samples were taken at 0,2 , $5,10,15,20,60,90,120$ and 150 minutes of reaction. The substrate concentration and product distributions were monitored using a gas chromatographic set-up (Bruker 456-GC with ECD and FID detectors, Headspace SHS-40) at it was reported earlier [25]. Samples after hydrodechlorination of TCE were labelled as spent-red-C-PdSiBEA, spent-red-CPdSiAlBEA and spent-red-C-PdHAlBEA, respectively.

\subsubsection{X-Ray Diffraction}

X-Ray Diffractograms (XRD) of as prepared samples were recorded at ambient atmosphere on a BRUKER D8 Advance diffractometer using the $\mathrm{Cu} \mathrm{K} \alpha$ radiation $(\lambda=154.05$ $\mathrm{pm})$ in the $2 \theta$ range of $5-90^{\circ}$. XRD profiles of samples after reduction and reaction were recorded on a Siemens D5000 diffractometer using $\mathrm{Ni}$-filtered $\mathrm{Cu} \mathrm{K} \alpha$ radiation in the $2 \theta$ range of $5-90^{\circ}$.

\subsubsection{Transmission Electron Microscopy}

Transmission Electron Microscopy (TEM) studies for the catalysts after reduction step and after catalytic reaction were carried out using JEOL JEM-100CXII electron microscope operated at an acceleration voltage of $100 \mathrm{keV}$. The samples before TEM investigations were dispersed in pure alcohol using ultrasonic cleaner and putting a drop of this suspension on carbon films on copper grids.

\section{Results and discussion}




\subsection{DR UV-vis studies}

Fig. 1 shows DR UV-Vis spectra of as prepared samples. DR UV-Vis spectrum of HAlBEA contains two bands at 220 and $270 \mathrm{~nm}$ probably related to $\mathrm{Al}$ species present in zeolite structure, in line with earlier report [26]. Process of dealumination changes the position of these bands from 220 to $206 \mathrm{~nm}$ and from 270 to $282 \mathrm{~nm}$ for SiAlBEA; from 220 to $200 \mathrm{~nm}$ and from 270 to $297 \mathrm{~nm}$ for SiBEA. On the other hand, the palladium-loaded BEA zeolites exhibit two characteristic bands at about $264-288$ and $390 \mathrm{~nm}$. First band can be assigned to oxygen-to-metal charge transfer (CT) transitions involving pseudo-tetrahedral Pd(II), while second one, wide and less intense, can be assigned to extra-framework octahedral Pd(II) [28-31]. The presence of extra-framework Pd(II) is confirmed by the light brown color of the samples.

\subsection{Physisorption studies}

The nitrogen adsorption-desorption isotherms of calcined zeolites and catalysts (Fig. 2) look similar and can be classified as type I according to IUPAC. All zeolite materials are characterized by BET surface area in the range of $310-477 \mathrm{~m}^{2} \mathrm{~g}^{-1}$ and pore volume in the range of $0.13-0.16 \mathrm{~cm}^{3} \mathrm{~g}^{-1}$ (Table 1). These comparable results indicate that the textural properties of BEA zeolite are preserved upon methods of their preparation. Generally, asprepared Beta zeolites have higher specific surface areas [32,33]. The decreasing of specific surface areas in C-SiBEA, C-SiAlBEA and C-HAlBEA in comparinon with as-prepared samples can be probably the effect of some blocking of the pore during the calcination. The incorporation of $\mathrm{Pd}^{2+}$ ions in as prepared Beta zeolites can stabilize the zeolite structure and prevent the blocking of pores during calcination, therefore there is more available space for nitrogen adsorption and in consequence higher surface areas, and micropores and mesopores volumes (Table 1).

\section{3. $\mathrm{H}_{2}-\mathrm{TPR}$ studies}


$\mathrm{H}_{2}$-TPR measurements were carried out to determine the differences in reducibility of palladium species present in C-PdSiBEA, C-PdSiAlBEA and C-PdHAlBEA zeolites. Each of TPR patterns contains three or four reduction peaks (Fig. 3). According to the literature $[27,34]$, the peaks with the maxima at the lowest temperatures $(260-273 \mathrm{~K})$ are originated from the reduction of $\mathrm{PdO}$ species located in main channels of zeolite and/or weakly bounded to zeolite structure. It is well known that $\mathrm{PdO}$ can be reduced in easy way at very low temperatures (even about $273 \mathrm{~K}$ ) on some supports [35]. The peaks with the maxima at higher temperatures $(311-318 \mathrm{~K})$ can be attributed to the reduction of octahedral $\mathrm{Pd}(\mathrm{II})$ present at extra-framework position, whereas the peaks at temperatures $347-382 \mathrm{~K}$ can be assigned to the reduction of mononuclear $\mathrm{Pd}(\mathrm{II})$ present in framework or exchange position, where the stabilization of $\mathrm{Pd}^{2+}$ ions is improved by higher negative charge density of the support [27, 34]. The negative $\mathrm{H}_{2}$ consumption peak at $380-407 \mathrm{~K}$ is usually ascribed to desorption of hydrogen from a bulk palladium hydride formed through hydrogen diffusion into Pd crystallites [36]. This behavior is observed when some amount of palladium is present in catalyst as large particles [37], what is in agreement with palladium particle size estimated from CO chemisorption, XRD and TEM.

\subsection{Chemisorption studies}

Chemisorption measurements allowed determining the Pd dispersion in reduced samples. Red-C-PdSiBEA, red-C-PdSiAlBEA and red-C-PdHAlBEA are characterized by the metal dispersion of 10,9 and $8 \%$, and the average Pd particles size (simply calculated from equation reported in [38]) of 11,13 and $14 \mathrm{~nm}$, respectively. These results are in agreement with results obtained by XRD and TEM (Table 2).

\subsection{TCE hydrodechlorination}

Fig. 4 shows the TCE conversion expressed as $C / C_{0}$ versus time of reaction carried out in the presence of red-C-PdSiBEA, red-C-PdSiAlBEA and red-C-PdHAlBEA zeolite 
catalysts. Palladium-loaded BEA zeolites are active catalysts in aqueous-phase hydrodechlorination of TCE. The decreasing of $\mathrm{pH}$ value (from 6.77 to 3.84) as a function of time indicates that hydrodechlorination process occurs. In the case of all catalysts, after 60 min of reaction almost $90 \%$ of TCE is removed from water. Chromatographic analysis of products formed during TCE HDC in the presence of red-C-PdSiBEA, red-C-PdSiAlBEA and red-C-PdHAlBEA shows mainly formation of non-chlorinated hydrocarbons (ethane and ethene).

A comparative study between red-C-PdSiBEA, red-C-PdSiAlBEA and red-CPdHAlBEA shows small differences in $\mathrm{C} / \mathrm{C}_{0}$ profiles (Fig. 4). The red-C-PdSiBEA indicates higher activity as $\mathrm{C} / \mathrm{C}_{0}$ after $20 \mathrm{~min}$ of reaction than red-C-PdSiAlBEA and red-CPdHAlBEA. The application of red-C-PdSiBEA with the highest Pd dispersion leads to removal almost $80 \%$ of TCE after first 20 min of hydrodechlorination, whereas only 70 and $65 \%$ of TCE is removed by red-C-PdSiAlBEA and red-C-PdHAlBEA, respectively.

These results suggest that the method of Pd-loaded BEA zeolite preparation plays a key role in TCE hydrodechlorination in aqueous-phase. As mentioned in Introduction part, there is some data in the literature concerning structure-sensitivity of aqueous-phases hydrodechlorination [15-20]. For example, Díaz et al. [17] carried out TCE hydrodechlorination in water using $0.5 \mathrm{wt}$ \% Pd supported on: activated carbon (AC), carbon nanofibers (CNF), high surface area graphites (HSAG), alumina and ZSM-5 zeolite. They obtained $\mathrm{Pd}$ nanoparticles in the range of $3-23 \mathrm{~nm}$ for different catalysts. The catalyst containing Pd nanoparticles with size $23 \mathrm{~nm}(0.5 \% \mathrm{Pd} / \mathrm{CNF})$ was found to be the most active in TCE hydrodechlorination.

On the other hand, results obtained by Śrębowata et al. [20] for Pd containing zeolites HZSM-5 and HZSM-5/DeSi indicated the beneficial role of very high Pd dispersion in hydrodechlorination of TCE in aqueous-phase. 
Analyzing the literature data [15-20] and the results of our work we assume that both smaller and larger Pd nanoparticles present in red-C-PdSiBEA, red-C-PdSiAlBEA and red-CPdHAlBEA play a role in aqueous-phase hydrodechlorination of TCE. In the presence of smaller Pd nanoparticles (red-C-PdSiBEA) the reaction occurs faster, but not completely (94 $\%$ of TCE conversion after $150 \mathrm{~min}$ ) probably due to nanoparticles deactivation. The reaction runs slower in the presence of larger nanoparticles (red-C-PdSiAlBEA and red-CPdHAlBEA), but after 150 min of reaction TCE is almost completely removed.

Hydrodechlorination of TCE over red-C-PdSiBEA, red-C-PdSiAlBEA and red-CPdHAlBEA is assumed to be pseudo-first-order due to the predominant amount of hydrogen compared to TCE. Fig. 5 shows the kinetic data according to the linearized pseudo-first-order rate equation. The reaction rate constants $k$, initial reaction rates $r_{0}$ and TOF values are presented in Table 3. Our results for red-C-PdSiBEA, red-C-PdSiAlBEA and red-CPdHAlBEA are comparable to the activity of catalysts with Pd supported on activated carbons, graphite, $\mathrm{CeO}_{2}$ [39-41], microporous and hierarchical zeolites [20] or CMCstabilized palladium nanoparticles [42].

\subsection{XRD studies}

Fig. 6 presents XRD patterns of as prepared samples. X-ray diffractograms of all the samples are similar and characteristic of BEA zeolite. It suggests that crystallinity of BEA zeolite is preserved after different zeolite treatment (dealumination, ion exchange and calcination) and introduction of Pd ions into zeolite structure.

The position of a main narrow diffraction peak near $22.8^{\circ}$ changes from $2 \theta$ of $22.76^{\circ}$ for HAlBEA to $2 \theta$ of $22.86^{\circ}$ for SiAlBEA and to $2 \theta$ of $22.88^{\circ}$ for SiBEA. The changes of main diffraction peak position is assigned to lattice contraction/expansion of the BEA structure, as reported earlier [43]. The significant shift to higher $2 \theta$ value after dealumination indicates contraction of the matrix as a result of $\mathrm{Al}$ removal $[44,45]$. 
The introduction of $1 \mathrm{wt} \%$ of Pd into SiBEA zeolite results in a shift of the main diffraction peak from $2 \theta$ of $22.88^{\circ}$ for SiBEA to $2 \theta$ of $22.58^{\circ}$ for PdSiBEA. The introduction of Pd into SiAlBEA yields a smaller shift from $2 \theta$ of $22.86^{\circ}$ for SiAlBEA to $2 \theta$ of $22.70^{\circ}$ for PdSiAlBEA. The introduction of Pd into HAlBEA does not lead to such significant change in the main diffraction peak position that was observed for SiBEA. In the former case, a small shift from $2 \theta$ of $22.76^{\circ}$ for HAlBEA to $2 \theta$ of $22.66^{\circ}$ for PdHAlBEA is observed. These phenomena indicate the expansion of the matrix as a result of the reaction between $\mathrm{Pd}$ ions and $\mathrm{OH}$ groups of vacant $\mathrm{T}$-atom sites $(\mathrm{T}=\mathrm{Si}$ or $\mathrm{Al})$ and $\mathrm{Pd}$ incorporation into BEA zeolite framework, as it was reported earlier [44, 46-48].

X-ray diffractograms of red-C-PdSiBEA, red-C-PdSiAlBEA and red-C-PdHAlBEA (Fig. 7) shows that the crystallinity of BEA zeolite is still preserved after calcination in air and reduction in $10 \% \mathrm{H}_{2} / \mathrm{Ar}$ flow, as reported earlier $[24,43,49,50]$. The characteristic reflection for Pd (111) at $2 \theta=40.15^{\circ}$ appeared after reduction in all reduced samples.

After calcination and reduction of PdSiBEA, the shift of the main characteristic diffraction peak of BEA zeolite to higher $2 \theta$ values is observed (from $2 \theta$ of $22.58^{\circ}$ for PdSiBEA to $2 \theta$ of $22.72^{\circ}$ for red-C-PdSiBEA). The contraction of BEA matrix can be explained by Pd output from framework position into extra-framework position and formation of $\mathrm{Pd}^{0}$ nanoparticles [43]. The reverse effect is noticed for palladium catalysts based on partial dealuminated and non-dealuminated zeolites. In these cases, the main diffraction peak of BEA zeolite is shifted to lower $2 \theta$ values (from $2 \theta$ of $22.70^{\circ}$ for PdSiAlBEA to $2 \theta$ of $22.56^{\circ}$ for red-C-PdSiAlBEA and from $2 \theta$ of $22.76^{\circ}$ for PdHAlBEA to $2 \theta$ of $22.36^{\circ}$ for red-CPdHAlBEA). This shift can be explained by presence in both PdSiAlBEA and PdHAlBEA samples mainly extra-framework Pd(II) species and their calcination could lead to incorporation of part of this extra-framework $\mathrm{Pd}(\mathrm{II})$ species in framework position with expansion of the BEA matrix and treatment with $\mathrm{H}_{2}$ at $873 \mathrm{~K}$ involve formation of $\mathrm{Pd}^{0}$ 
nanoparticles in extra-framework position of red-C-PdSiAlBEA and red-C-PdHAlBEA mainly from extra-framework Pd(II) species. Similar results were observed for other metalloaded BEA zeolites [43].

XRD results obtained for catalysts after reduction and after hydrodechlorination of TCE show that the crystal structure of BEA is preserved (Fig. 7). For catalysts based on SiBEA and SiAlBEA supports inverse shift of the main diffraction peak after reaction with TCE is observed from $2 \theta$ of $22.72^{\circ}$ for red-C-PdSiBEA to $2 \theta$ of $22.86^{\circ}$ for spent-red-CPdSiBEA and from $2 \theta$ of $22.56^{\circ}$ for red-C-PdSiAlBEA to $2 \theta$ of $22.40^{\circ}$ for spent-red-CPdSiAlBEA. These inverse effects can be explained by partial removal of Pd from framework of red-C-PdSiBEA and partial oxidation of extra-framework Pd nanoparticles of red-CPdSiAlBEA upon hydrochlorination of TCE with formation of $\mathrm{Pd}(\mathrm{II})$ species which can migrate and incorporate into zeolite framework in reaction condition [51]. The shift of main diffraction peak from $2 \theta$ of $22.36^{\circ}$ for red-C-PdHAlBEA to $2 \theta$ of $22.52^{\circ}$ for spent-red-CPdHAlBEA is probably a result of carbon species formation and/or irreversible adsorption of $\mathrm{HCl}$ occurred in the zeolite $[52,53]$.

\subsection{TEM studies}

TEM measurements allowed to determine the Pd particles size distribution in red-CPdSiBEA, red-C-PdSiAlBEA and red-C-PdHAlBEA. All samples reduced at $873 \mathrm{~K}$ for $3 \mathrm{~h}$ are characterized by the dispersion of $10-14 \%$ and the average Pd particle size in the range of 8-14 nm (Table 2). These values are in very good agreement with chemisorption and XRD results (Table 2).

TEM images of red-C-PdSiBEA, red-C-PdSiAlBEA and red-C-PdHAlBEA and palladium particles size distributions are shown in Fig. 8a, 9a and 10a. The presented histograms exhibit rather uniform distribution of metallic nanoparticles. In all catalysts, $\mathrm{Pd}$ is very good dispersed in zeolite material. The average nanoparticles sizes are similar for all 
catalysts (Table 2). However, almost $47 \%$ of small nanoparticles $(1-6 \mathrm{~nm})$ is present in redC-PdSiBEA (Fig. 8a), whereas only 36 and $34 \%$ is present in red-C-SiAlBEA (Fig. 9a) and red-C-HAlBEA (Fig. 10a), respectively. This means that the way of catalysts preparation has an impact on metal particles diameter and particles distribution. Smaller Pd nanoparticles after reduction step are obtained due to the impregnation of completely dealuminated BEA zeolite ( $\mathrm{SiBEA}$ ) by $\mathrm{PdCl}_{2}$ aqueous solution and incorporation of $\mathrm{Pd}$ ions into zeolite structure in framework position. However, after impregnation of partially dealuminated (SiAlBEA) and non-dealuminated (HAlBEA) zeolites by $\mathrm{PdCl}_{2}$ aqueous solution, $\mathrm{Pd}$ ions are introduced mainly in extra-framework position what gives after reduction step larger metal particles, in particular in red-C-PdHAlBEA.

TEM images, palladium particles size distribution and XRD results for catalysts after reaction (Table 2, Fig. $\mathbf{8 b}, \mathbf{9 b}$ and $\mathbf{1 0 b}$ ) show that Pd nanoparticles are slightly larger than that observed in the case of catalysts after reduction step, what can be associated with migration and agglomeration of metal particles during reaction.

\section{Conclusions}

In this work we have shown that the method of catalysts synthesis has the influence on the distribution of Pd nanoparticles and impact on their catalytic activity in aqueous-phase hydrodechlorination of TCE.

The two-step postsynthesis method and full dealumination of BEA zeolite allowed obtaining the smallest and most active Pd nanoparticles (removal of $80 \%$ TCE after 20 min of reaction) as opposed to the conventional wet impregnation (removal only of $65 \%$ TCE after the same time). 


\section{Acknowledgements}

This work was partially financed by Grant No. 2011/03/D/ST5/05516 from the National

Science Centre, Poland. The synthesis and partially characterization of Pd-loaded BEA zeolites were carried out within GDRI PAN-CNRS program (Catalysis for Environment: Depollution, Renewable Energy and Clean Fuels).

\section{References}

[1] Bouriazos A., Sotiriou S., Stathis P., Papadogianakis G., Appl. Catal. B, 150-151 (2014) $345-353$

[2] Yuan T., Gong H., Kailasam K., Zhao Y., Thomas A., Zhu J., J. Catal., 326 (2015) 38-42

[3] Figueira C.A., Lopes P.S., Gomes P.T., Tetrahedron, 71 (2015) 4362-4371

[4] Akbayrak S., Kaya M., Volkan M., Özkar S., Appl. Catal. B, 147 (2014) 387-393

[5] Kim J., Zhang P., Li J., Wang J., Fu P., Chem. Eng. J, 252 (2014) 337-345

[6] Chen M., Qi L., Fan L., Zhou R., Zheng X., Mater. Lett., 62 (2008) 3646-3648

[7] Anulewicz P.A., White R.F., Martin B.M., Winter M.R., Weinberg J.M., Vieira V., Aschengrau A., Neurotoxicol. Teratol., 34 (2012) 350-359

[8] Rusyn I., Chiu W.A., Lash L.H., Kromhout H., Hansen J., Guyton K.Z., Pharmacol. Therap., 141 (2014) 55-68

[9] Guha N., Loomis D., Grosse Y., Lauby-Secretan B., El Ghissassi F., Bouvard V., Benbrahim-Tallaa L., Baan R., Mattock H., Straif K., Lancet Oncol., 13 (2012) 1192-1193 [10] Han Y., Gu G., Sun J., Wang W., Wan H., Xu Z., Zheng Sh., Appl. Surf. Sci., 355 (2015) $183-190$

[11] Zhang M., Bacik D.B., Roberts Ch.B., Zhao D., Water Res., 47 (2013) 3706-3715

[12] Navon R., Eldad Sh., Mackenzie K., Kopinke F.-D., Appl. Catal. B, 119-120 (2012) 241247 
[13] Park J., Joo J., Kwon S.G., Jang Y., Hyeon T., Angew. Chem., Int. Ed., 46 (2007), 46304660

[14] Baeza J.A., Calvo L., Gilarranz M.A., Mohedano A.F., Casas J.A., Rodriguez J.J., J. Catal., 293 (2012) 85-93

[15] Juszczyk W., Malinowski A., Karpiński Z., Appl. Catal. A., 166 (1998) 311-319

[16] Aramendía M.A., Boráu V., García I.M., Jiménez C., Lafont F., Marinas A., Marinas J.M., Urbano F.J., J. Catal., 187 (1999) 392-399

[17] Díaz E., McCall A., Faba L., Sastre H., Ordonez S., Environ. Prog. Sustainable Energy, 32 (2013) 1217-1222

[18] Gómez-Quero S., Cárdenas-Lizana F., Keane M.A., Ind. Eng. Chem. Res., 47 (2008), $6841-6853$

[19] Dong Z., Le X., Liu Y., Dong Ch., Ma J., J. Mater. Chem. A, 2 (2014) 18775-18785

[20] Śrębowata A., Tarach K., Girman V., Góra-Marek K., Appl. Catal. B, 181 (2016) 550560

[21] Ardila A.N., Reyes J., Arriola E., Hernández J.A., Fuentes G.A., Appl. Catal. A, 497 (2015) 211-215

[22] Imre B., Hannus I., Kiricsi I., J. Mol. Struct., 744-747 (2005) 501-506

[23] Hannus I., Főző M., Halász J., Tasi G., Stud. Surf. Sci. Catal., 158 (2005) 1803-1810

[24] Śrębowata A., Baran R., Łomot D., Lisovytskiy D., Onfroy T., Dzwigaj S., Appl. Catal. B, 147 (2014) 208-220

[25] Śrębowata A., Kamińska I.I., Giziński D., Wideł D., Oszczudłowski J., Catal. Today, 251 (2015) 60-65

[26] Novak Tusar N., Mali G., Arcon I., Kaucic V., Ghanbari-Siahkali A., Dwyer J., Micropor. Mesopor. Mater., 55 (2002) 203-216 
[27] Roldán R., Beale A.M., Sánchez-Sánchez M., Romero-Salguero F.J., JiménezSanchidrián C., Gómez J.P., Sankar G., J. Catal., 254 (2008) 12-26

[28] Zhang Z., Sachtler W.M.H., Zeolites, 10 (1990) 784-789

[29] Okitsu K., Bandow H., Maeda Y., Chem. Mater., 8 (1996) 315-317

[30] Shimizu K., Maruyama R., Komai S., Kodama T., Kitayama Y., J. Catal., 227 (2004) 202-209

[31] Celebi M., Yurderi M., Bulut A., Kaya M., Zahmakiran M., Appl. Catal. B, 180 (2016) $53-64$

[32] Boroń P., Chmielarz L., Gil B., Marszałek B., Dzwigaj S., Appl. Catal. B, 198 (2016) $457-470$

[33] Kyriienko P.I., Larina O V., Popovych N.O., Soloviev S.O., Millot Y., Dzwigaj S., J. Mol. Catal. A: Chem., 424 (2016) 27-36

[34] Yang K., Wang B., Chen L., Wang X., Catal. Commun., 9 (2008) 431-436

[35] Bendahou K., Cherif L., Siffert S., Tidahy H.L., Benaïssa H., Aboukaïs A., Appl. Catal. A, $351(2008) 82-87$

[36] Vannice M.A., Chou P., J. Catal., 107 (1987) 129-139

[37] Echeandia S., Pawelec B., Barrio V.L., Arias P.L., Cambra J.F., Loricera C.V., Fierro J.L.G., Fuel, 117 (2014) 1061-1073

[38] Ichikawa S., Poppa H., Boudart M., J. Catal. 91 (1985) 1-10

[39] Cobo M., Becerra J., Costelblanco M., Cifuentes B., Conesa J.A., J. Environ. Menag., $158(2015) 1-10$

[40] Molina C.B., Pizarro A.H., Casas J.A., Rodrigues J.J., Appl. Catal. B, 148-149 (2014) $330-338$

[41] Díaz E., Faba L., Ordóñez S. Appl. Catal. B, 104 (2011) 415-417

[42] Zhang M., Bacik D.B., Roberts Ch.B., Zhao D., Water Res., 47 (2013), 3706-3715 
[43] Śrębowata A., Baran R., Casale S., Kamińska I.I., Łomot D., Lisovytskiy D., Dzwigaj S., Appl. Catal. B, 152-153 (2014) 317-327

[44] Dzwigaj S., Peltre M.J., Massiani P., Davidson A., Che M., Sen T., Sivasanker S., Catal. Comm., 87 (1988)

[45] Dzwigaj S., Matsuoka M., Franck R., Anpo M., Che M., J. Phys. Chem. B, 102 (1998) $6309-6312$

[46] Dzwigaj S., Massiani P., Davidson A., Che M., J. Mol. Catal. A: Chem., 155 (2000) 169182

[47] Dzwigaj S., Janas J., Gurgul J., Socha R.P., Shishido T., Che M., Appl. Catal. B, 85 (2009) 131-138

[48] Janas J., Gurgul J., Socha R.P., Kowalska J., Nowinska K., Shishido T., Che M., Dzwigaj S., J. Phys. Chem. C, 113 (2009) 13273-13281

[49] Śrębowata A., Baran R., Kamińska I.I., Onfroy T., Krafft J.-M., Dzwigaj S., Catal. Today, 251 (2015) 73-80

[50] Śrębowata A., Zielińska I., Baran R., Słowik G., Dzwigaj S., Catal. Comm., 69 (2015) $154-160$

[51] Śrębowata A., Baran R., Lisovytskiy D., Kamińska I.I., Dzwigaj S., Catal. Comm., 57 (2014) $107-110$

[52] Hannus I., Appl. Catal. A, 189 (1999) 263-276

[53] Shalygin A.S., Malysheva L.V., Paukshtis E.A., Kinet. Catal., 52 (2011) 305-315 
Table 1. Specific surfaces areas and pore volumes determined from the nitrogen adsorptiondesorption isotherms of calcined zeolites and catalysts.

\begin{tabular}{|c|c|c|c|c|}
\hline \multirow{2}{*}{ Sample } & BET specific & Micropore & Mesopore & Total pore \\
& surface area & volume & volume & volume \\
$\left(\mathrm{m}^{2} \mathrm{~g}^{-1}\right)$ & $\left(\mathrm{cm}^{3} \mathrm{~g}^{-1}\right)$ & 0.12 & 0.04 & 0.16 \\
\hline C-SiBEA & 374 & 0.13 & 0.03 & 0.16 \\
\hline C-PdSiBEA & 393 & 0.09 & 0.03 & 0.15 \\
\hline C-SiAlBEA & 310 & 0.10 & 0.06 & 0.16 \\
\hline C-PdSiAlBEA & 447 & 0.10 & 0.03 & 0.13 \\
\hline C-HAlBEA & 329 & 0.10 & 0.04 & 0.14 \\
\hline C-PdHAlBEA & 377 & & & \\
\hline
\end{tabular}


Table 2. Palladium particle sizes estimated from $\mathrm{CO}$ chemisorption, XRD and TEM measurements.

\begin{tabular}{|c|c|c|c|c|}
\hline \multirow{2}{*}{ Sample } & \multicolumn{2}{|c|}{ Palladium particle size (nm) estimated from } & \multirow{2}{*}{ Dispersion $^{\text {b }}$} \\
\cline { 2 - 5 } & CO & XRD & TEM $^{\mathrm{a}}$ & $(\%)$ \\
\hline red-C-PdSiBEA & 11 & 10 & 8 & 14 \\
\hline spent-red-C-PdSiBEA & - & 17 & 9 & 12 \\
\hline red-C-PdSiAlBEA & 13 & 10 & 9 & 12 \\
\hline spent-red-C-PdSiAlBEA & - & 10 & 9 & 12 \\
\hline red-C-PdHAlBEA & 14 & 10 & 9 & 10 \\
\hline spent-red-C-PdHAlBEA & - & 10 & 11 & 12 \\
\hline
\end{tabular}

${ }^{\mathrm{a}}$ the average distribution of $\mathrm{Pd}$ nanoparticles

${ }^{\mathrm{b}}$ calculated form equation $\mathrm{D}(\%)=(1.12 / \mathrm{d}) \times 100 \%$, where $\mathrm{d}(\mathrm{nm})$ is the average $\mathrm{Pd}$ nanoparticles size estimated from TEM measurements [41] 
Table 3. The reaction rate constant $\mathrm{k}$, coefficient of determination $\mathrm{R}^{2}$, initial reaction rate $\mathrm{r}_{0}$ and TOF values for hydrodechlorination of TCE at $303 \mathrm{~K}$ on PdBEA zeolites.

\begin{tabular}{|c|c|c|c|c|}
\hline Sample & $\mathrm{k}^{\mathrm{a}}\left(\mathrm{min}^{-1}\right)$ & $\mathrm{R}^{2}$ & $\mathrm{r}_{0}^{\mathrm{b}}\left(\mathrm{mol} \mathrm{s}^{-1}\right.$ & $\mathrm{TOF}^{\mathrm{c}}\left(\mathrm{s}^{-1}\right) \times$ \\
$\left.\mathrm{g}_{\mathrm{Pd}}^{-1}\right) \times 10^{-4}$ & $10^{-2}$ \\
\hline red-C-PdSiBEA & 0.1365 & 0.9406 & 2.56 & 19.45 \\
\hline red-C-PdSiAlBEA & 0.0907 & 0.9364 & 2.11 & 18.67 \\
\hline red-C-PdHAlBEA & 0.0707 & 0.8083 & 1.76 & 15.61 \\
\hline
\end{tabular}

${ }^{\mathrm{a}}$ the reaction rate constant $\mathrm{k}$ calculated from equation $\ln \left(\mathrm{C} / \mathrm{C}_{0}\right)=-\mathrm{kt}$, where $\mathrm{k}$ is first-order rate constant $\left(\mathrm{min}^{-1}\right)$ and $\mathrm{t}$ is reaction time (min)

${ }^{\mathrm{b}}$ the initial reaction rate calculated from equation: $\mathrm{r}_{0}\left(\mathrm{~mol} \mathrm{~s}^{-1} \mathrm{~g}_{\mathrm{Pd}}{ }^{-1}\right)=\left(\mathrm{n}_{\mathrm{t}=0}-\mathrm{n}_{\mathrm{t}=600}\right) /\left(\Delta \mathrm{t} \times \mathrm{m}_{\mathrm{Pd}}\right)$, where $\mathrm{n}_{\mathrm{t}=0}(\mathrm{~mol})$ - the initial amount of TCE moles, $\mathrm{n}_{\mathrm{t}=600}(\mathrm{~mol})-$ amount of TCE moles after 600 seconds of reaction, $\Delta t(s)=600-$ initial reaction time, $m_{P d}(g)-$ mass of $P d$ in the catalyst [39]

${ }^{\mathrm{c}}$ TOF calculated from equation: TOF $\left(\mathrm{s}^{-1}\right)=\left(\mathrm{r}_{0} \times \mathrm{M} \times 100\right) / \mathrm{D}$, where $\mathrm{r}_{0}\left(\mathrm{~mol} \mathrm{~s}^{-1} \mathrm{~g}_{\mathrm{Pd}}{ }^{-1}\right)-$ the initial reaction rate, $\mathrm{M}\left(\mathrm{g} \mathrm{mol}^{-1}\right)$ - atomic mass of $\mathrm{Pd}, \mathrm{D}(\%)$ - metal dispersion [40] 


\section{Figure captions:}

Fig. 1. DR UV-Vis spectra recorded at ambient atmosphere of as prepared SiBEA, PdSiBEA, SiAlBEA, PdSiAlBEA, HAIBEA and PdHAIBEA.

Fig. 2. Adsorption and desorption isotherms of $\mathrm{N}_{2}$ at $77 \mathrm{~K}$ of calcined C-SiBEA, C-PdSiBEA, C-SiAlBEA, C-PdSiAlBEA, C-HAlBEA and C-PdHAlBEA. Empty symbols: adsorption; full symbols: desorption.

Fig. 3. TPR patterns of calcined C-PdSiBEA, C-PdSiAlBEA and C-PdHAlBEA.

Fig. 4. Kinetics of TCE hydrodechlorination at $303 \mathrm{~K}$ in the presence of red-C-PdSiBEA, redC-PdSiAlBEA and red-C-PdHAlBEA.

Fig. 5. Plots of $\ln \left(\mathrm{C} / \mathrm{C}_{0}\right)$ versus reaction time for hydrodechlorination of TCE at $303 \mathrm{~K}$ on redC-PdSiBEA, red-C-PdSiAlBEA and red-C-PdHAlBEA.

Fig. 6. XRD patterns recorded at ambient atmosphere of as prepared SiBEA, PdSiBEA, SiAlBEA, PdSiAlBEA, HAlBEA and PdHAlBEA recorded at ambient atmosphere.

Fig. 7. XRD patterns recorded at ambient atmosphere of samples after reduction (red-CPdSiBEA, red-C-PdSiAlBEA and red-C-PdHAlBEA) and after reaction with TCE (spent-redC-PdSiBEA, spent-red-C-PdSiAlBEA and spent-red-C-PdHAlBEA).

Fig. 8. TEM images and Pd particle size distribution of a) red-C-PdSiBEA and b) spent-redC-PdSiBEA.

Fig. 9. TEM images and Pd particle size distribution of a) red-C-PdSiAlBEA and b) spentred-C-PdSiAlBEA.

Fig. 10. TEM images and Pd particle size distribution of a) red-C-PdHAlBEA and b) spentred-C-PdHAlBEA. 


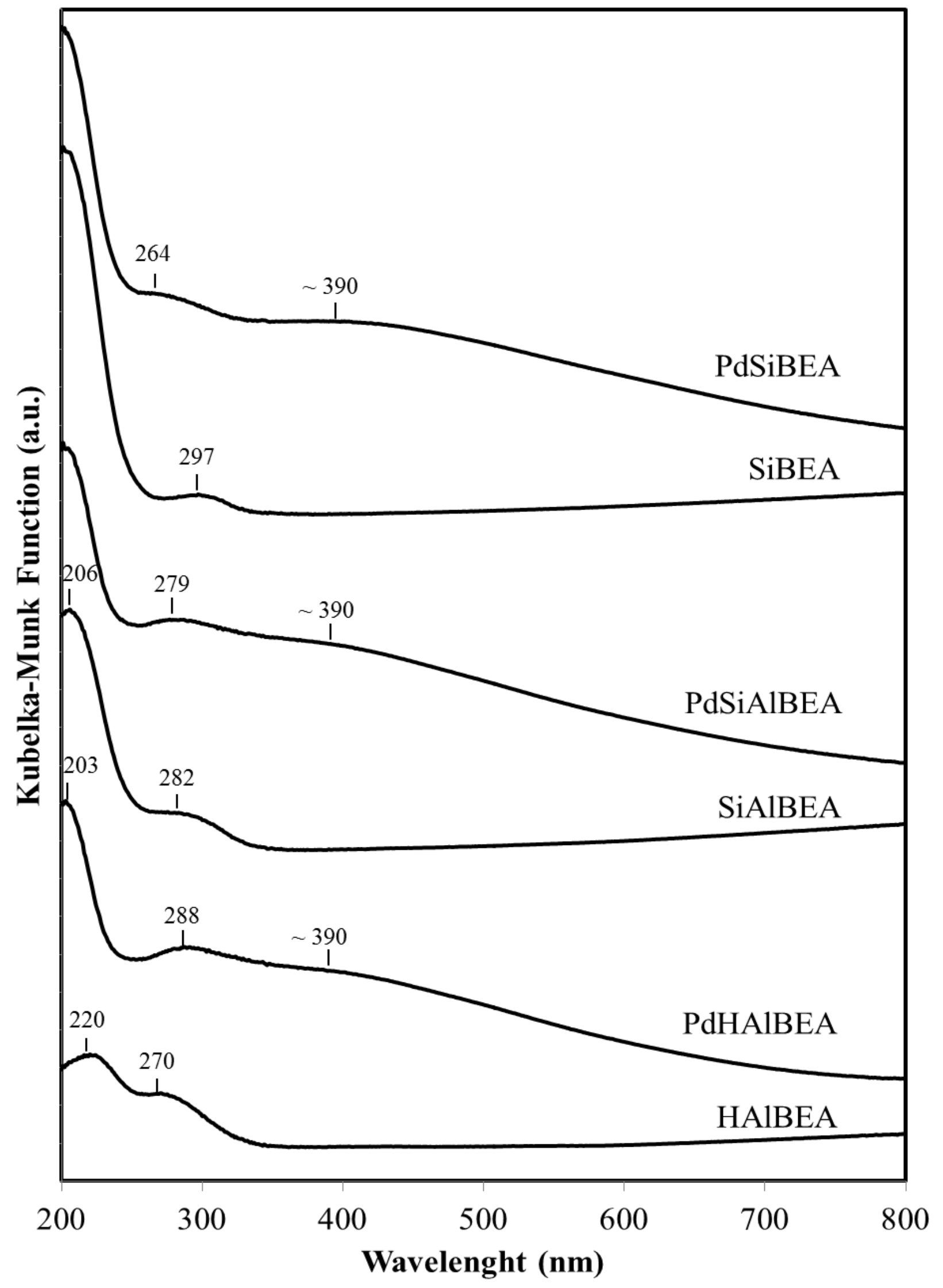

Fig. 1. 


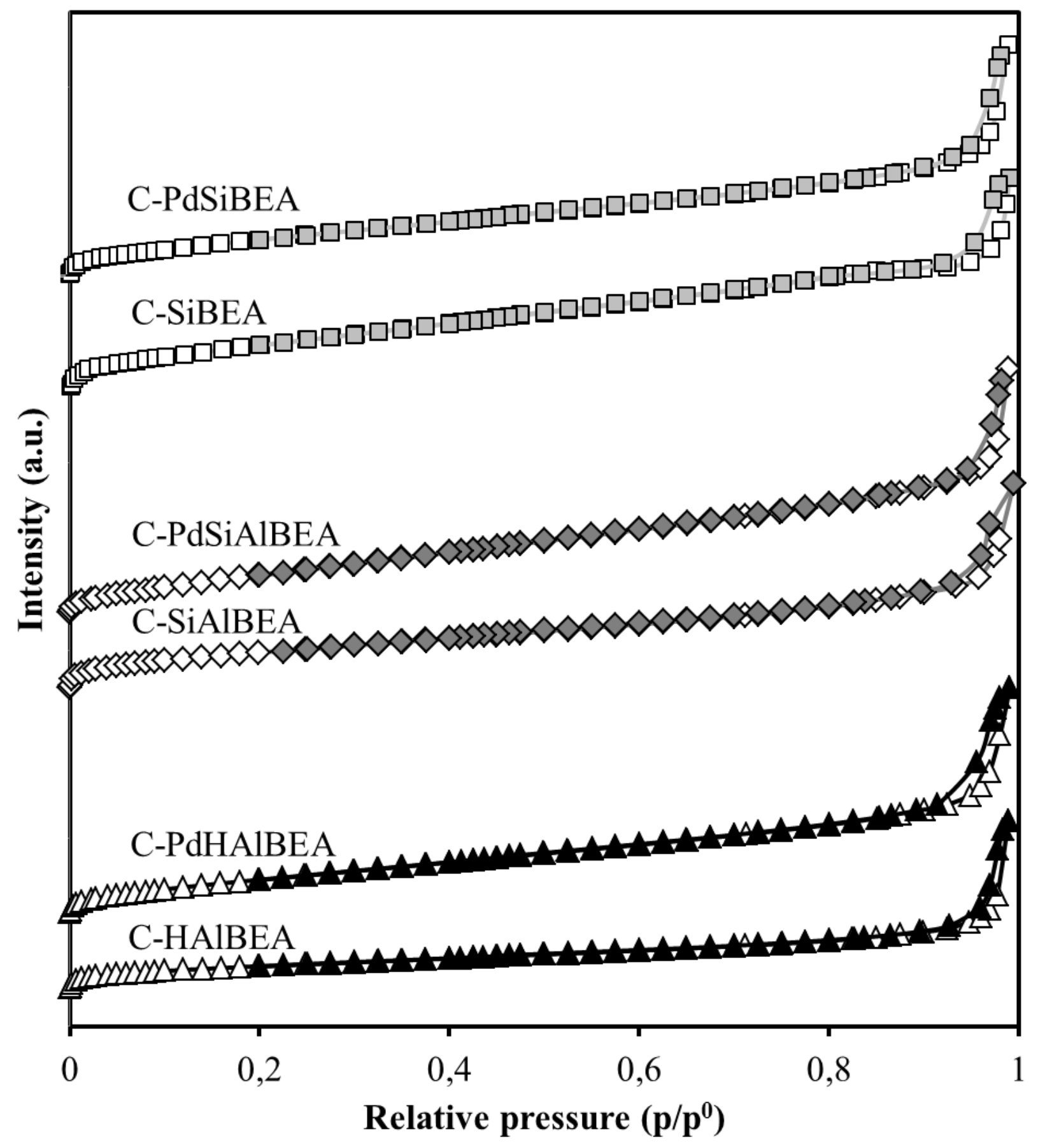

Fig. 2. 


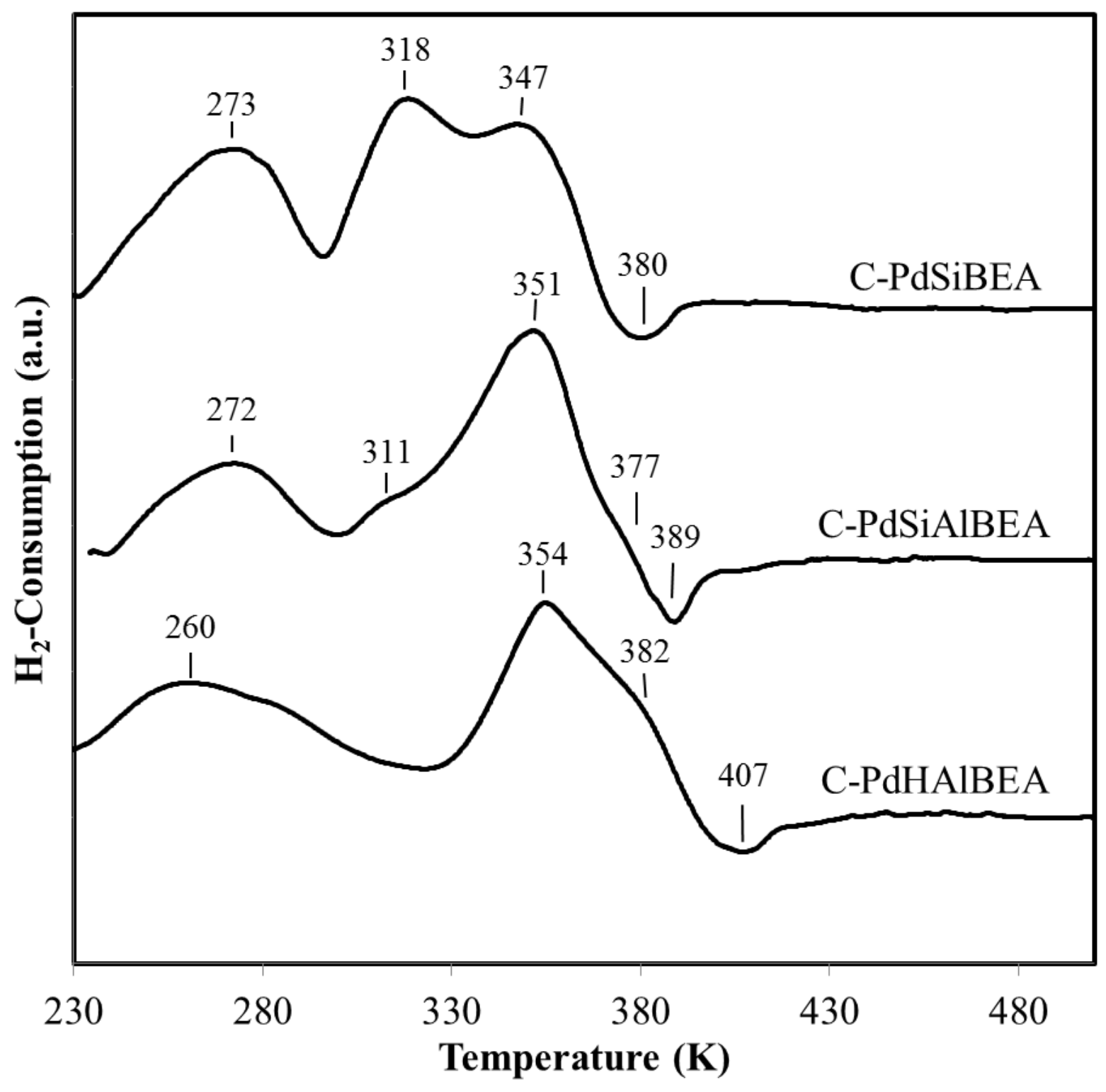

Fig. 3. 


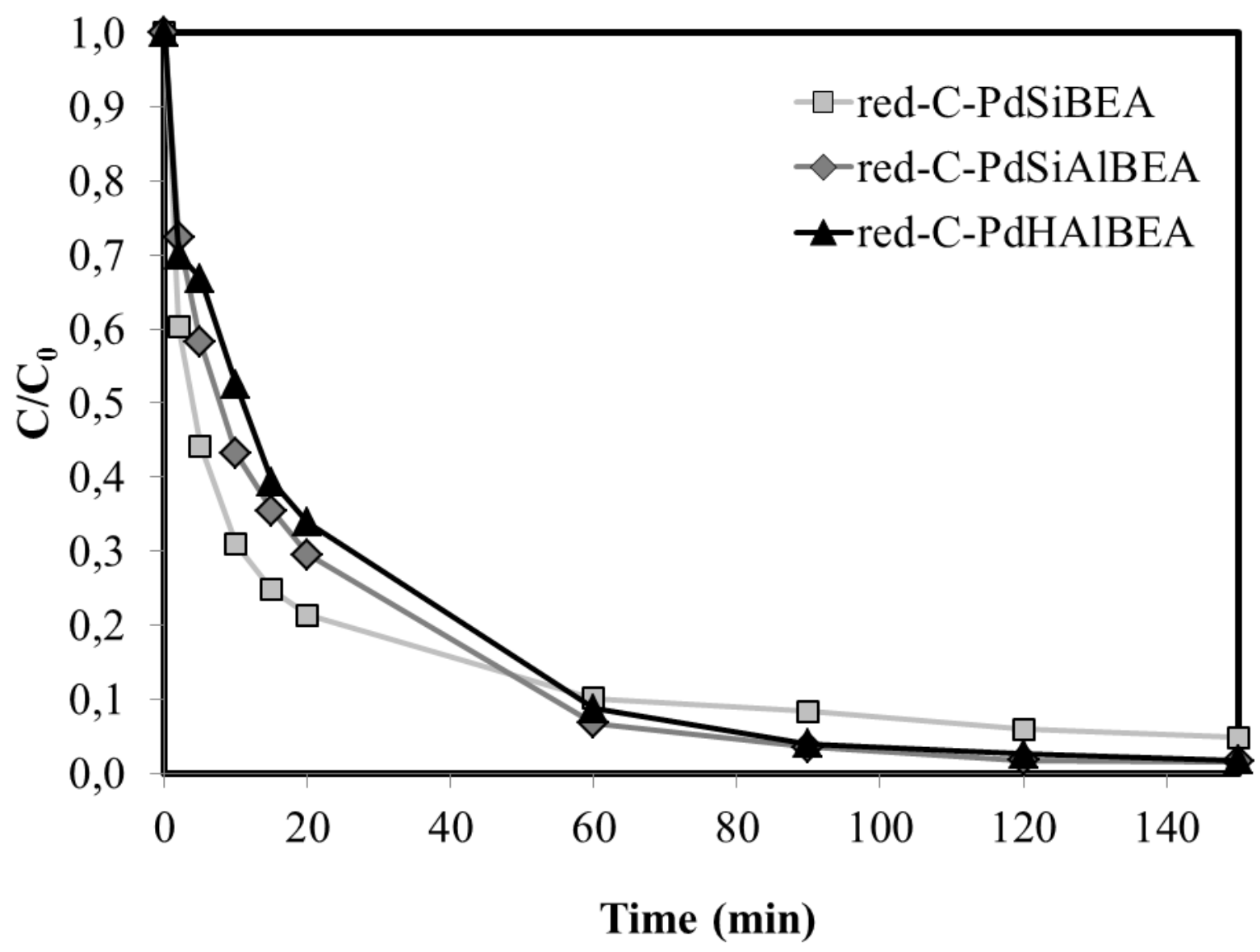

Fig. 4. 


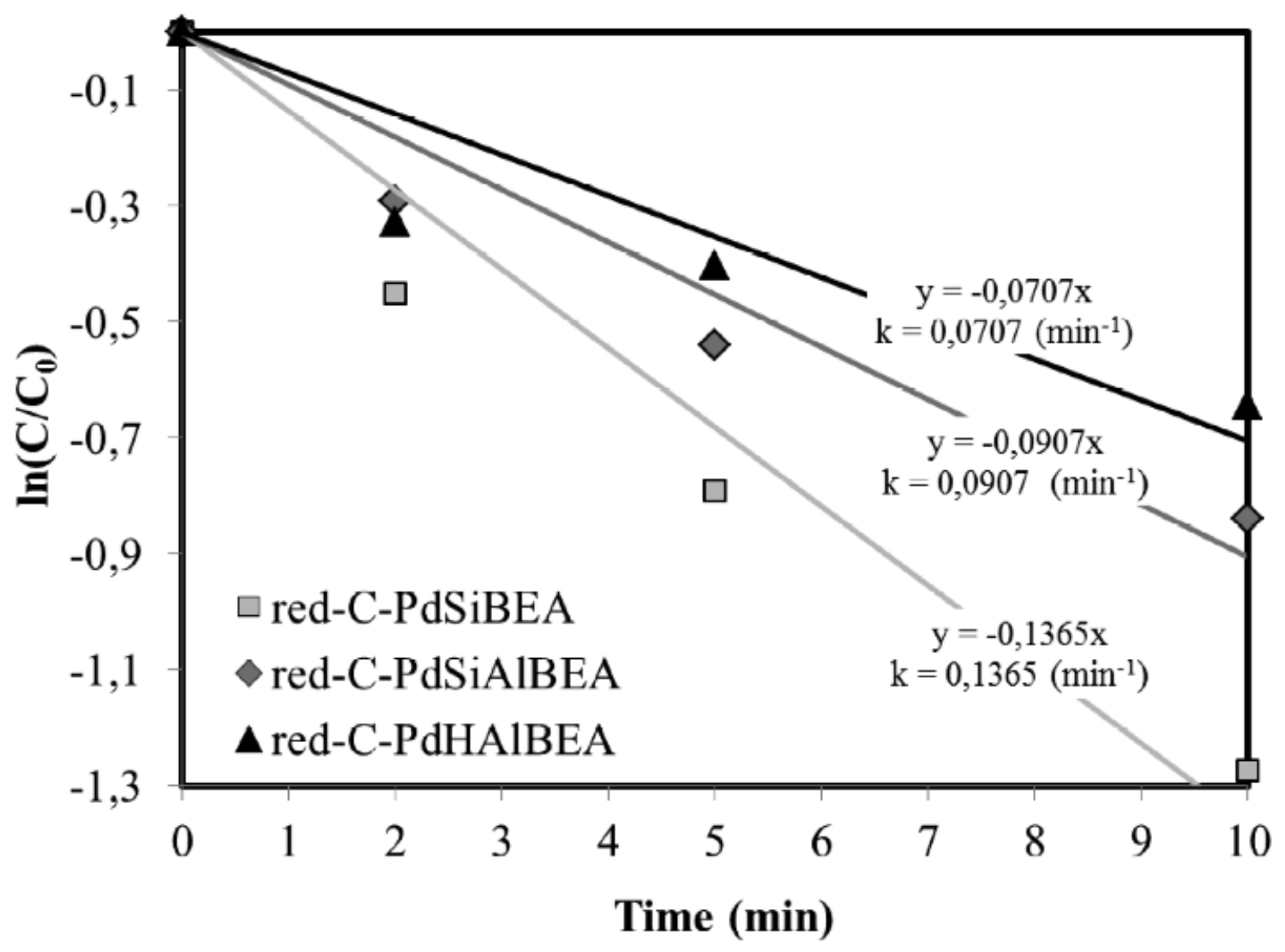

Fig. 5. 


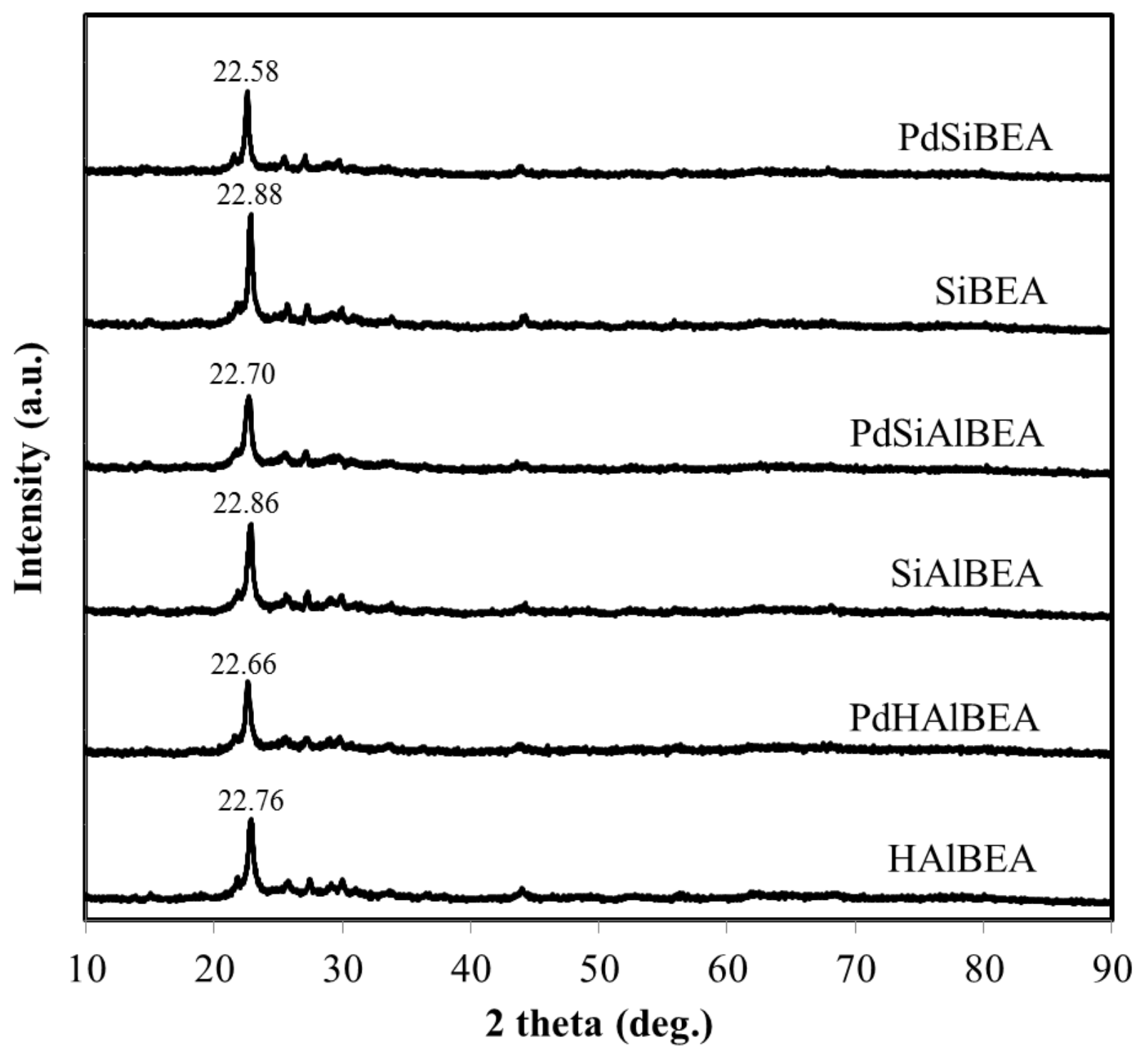

Fig. 6. 


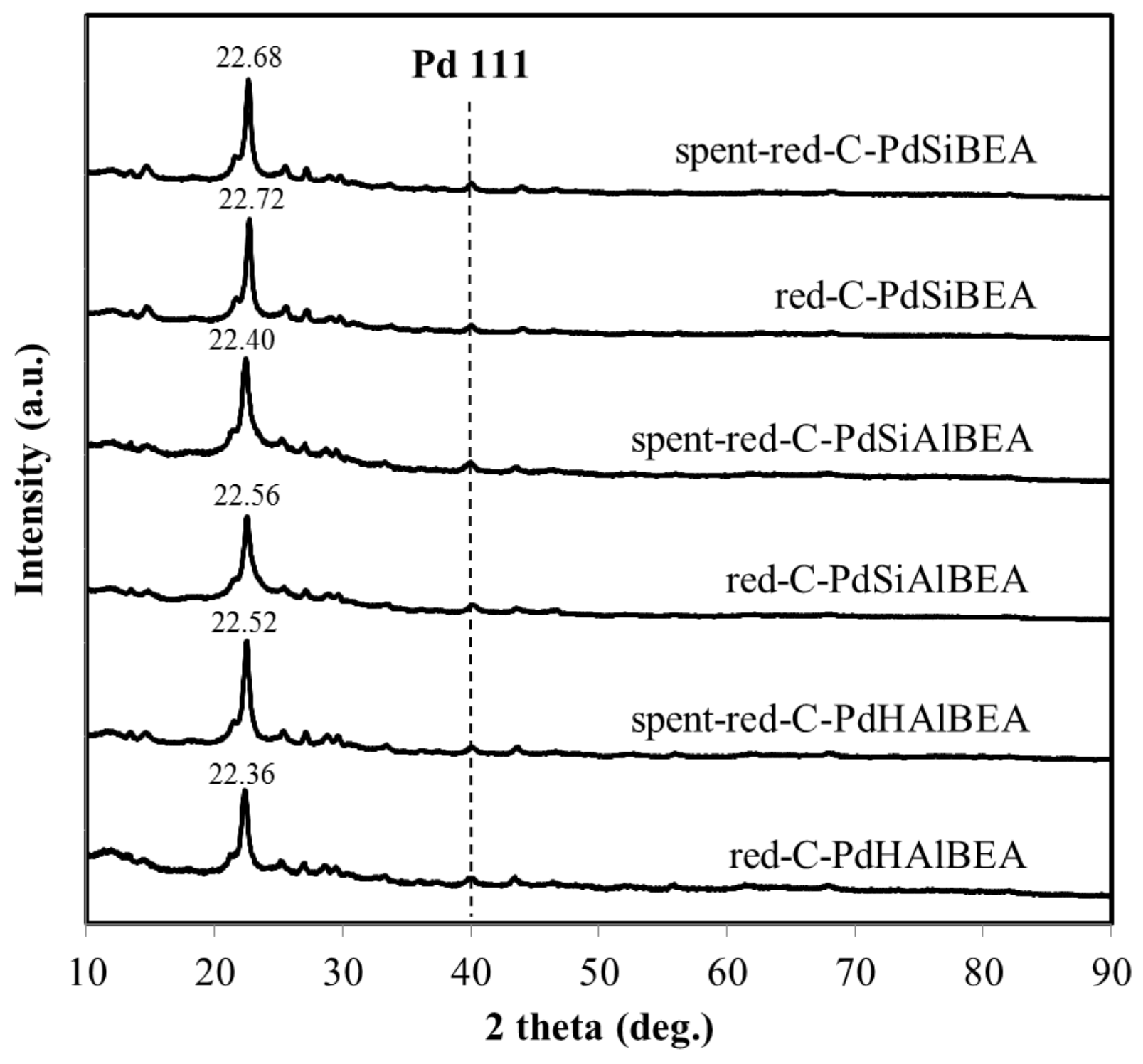

Fig. 7. 

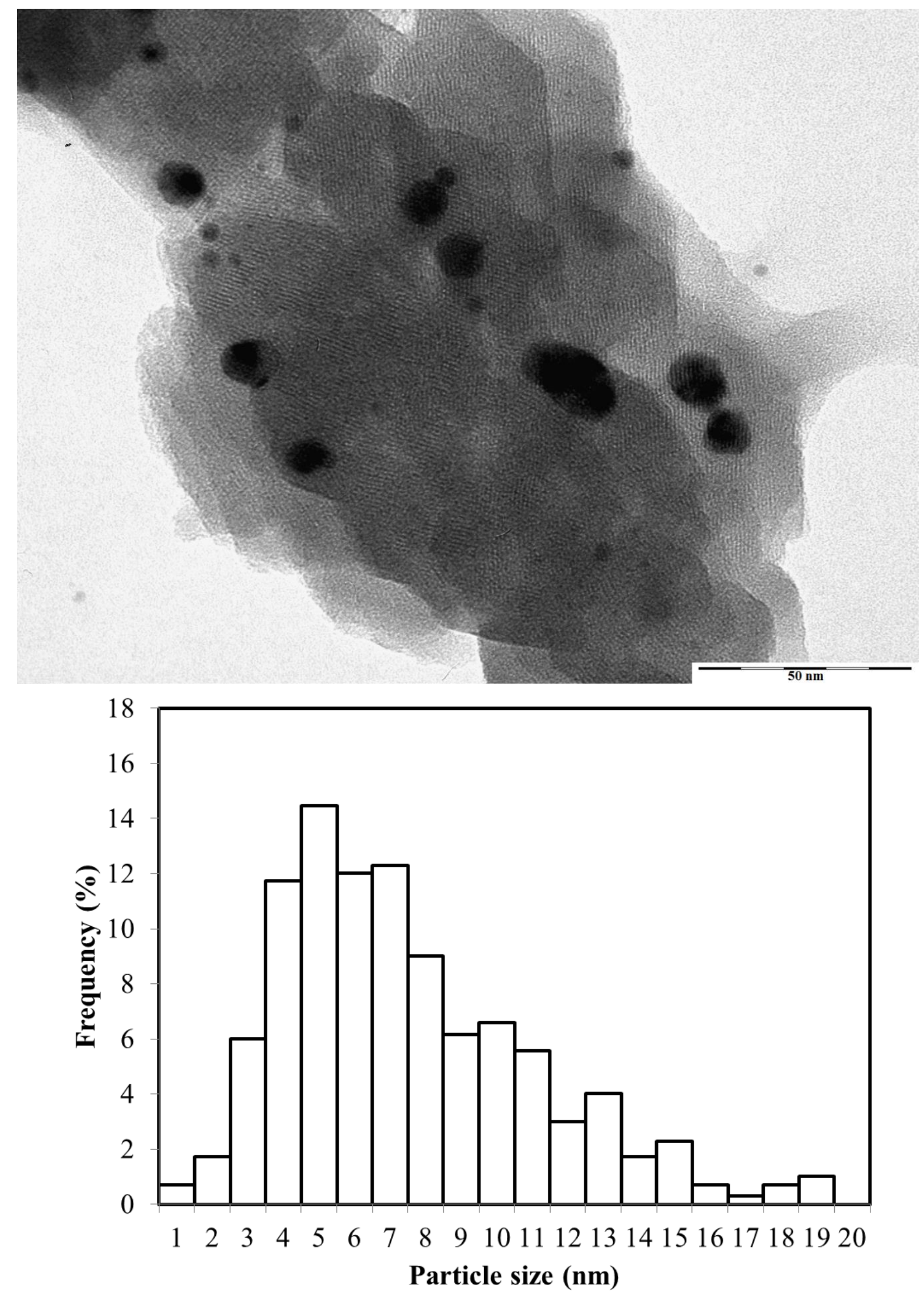

Fig. 8a 

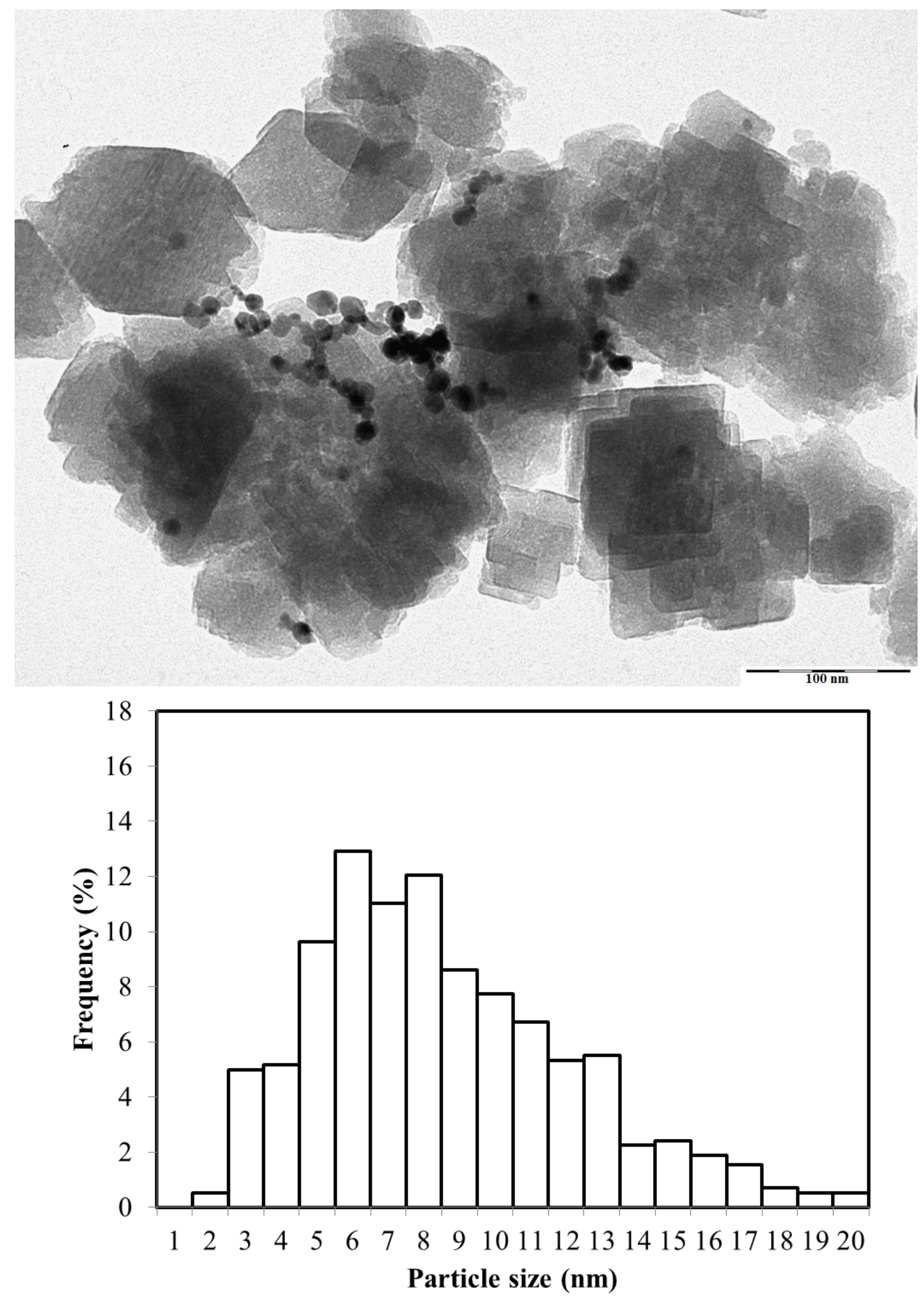

Fig. 8b 

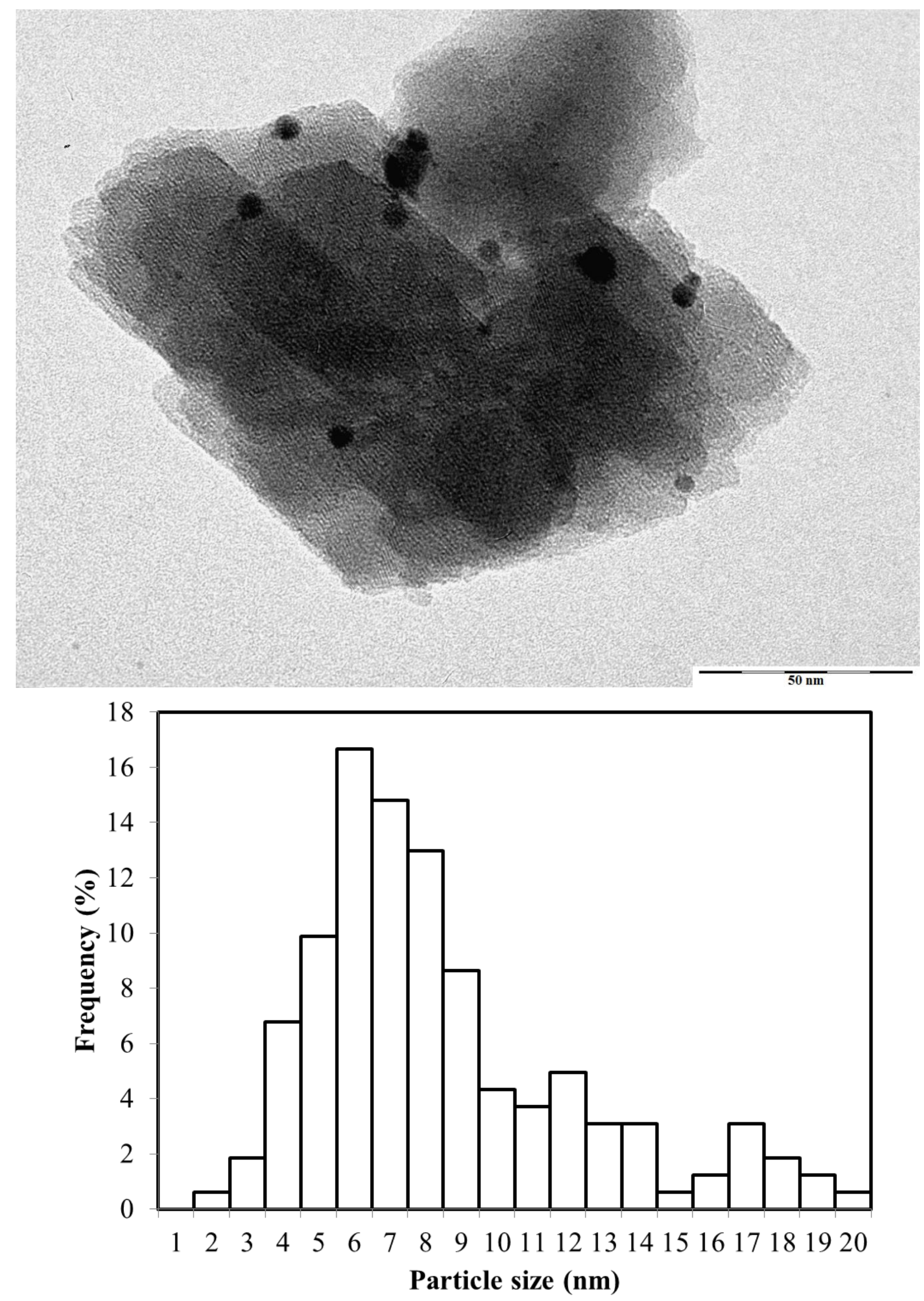

Fig. 9a 

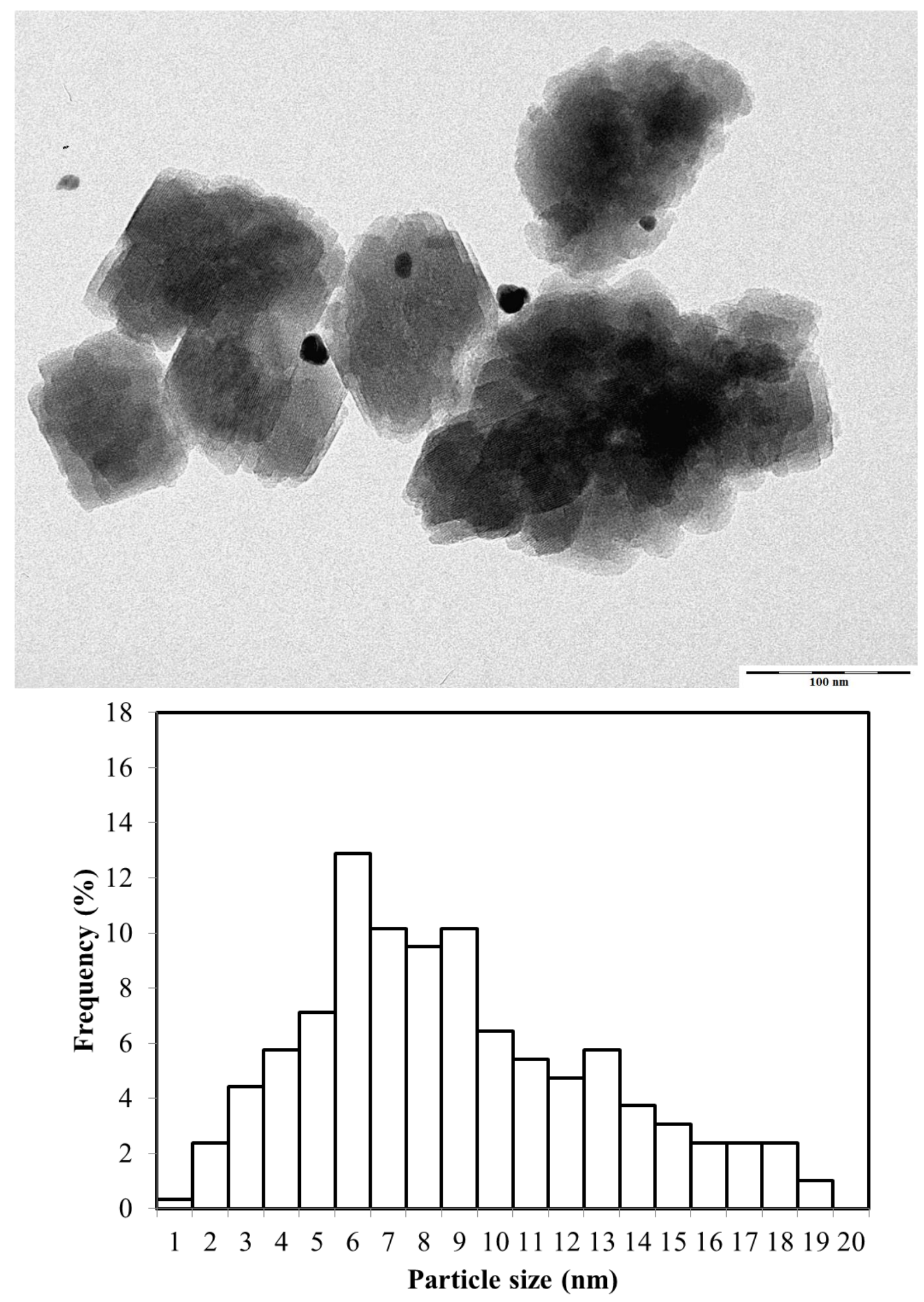

Fig. 9b 

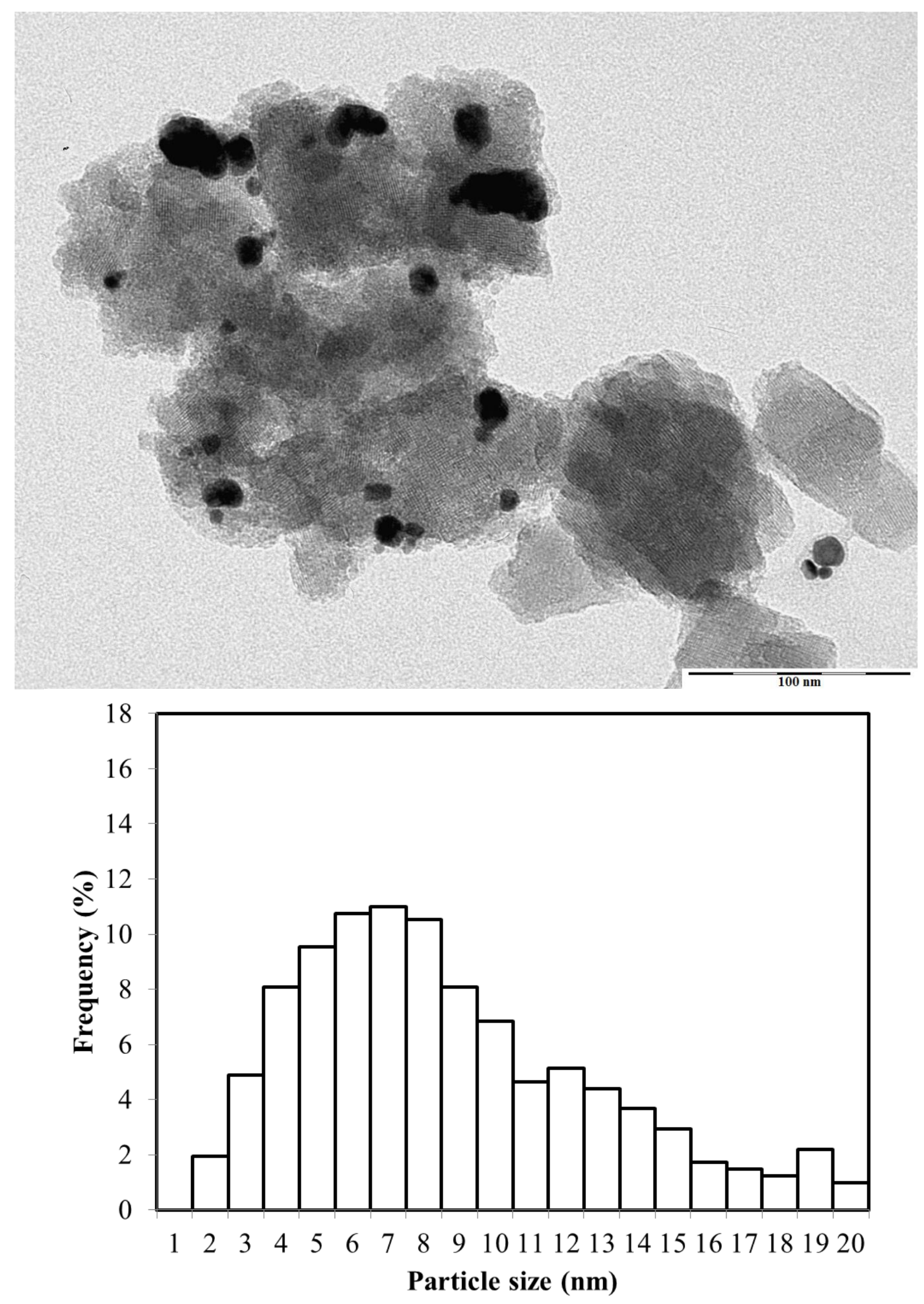

Fig. 10a 

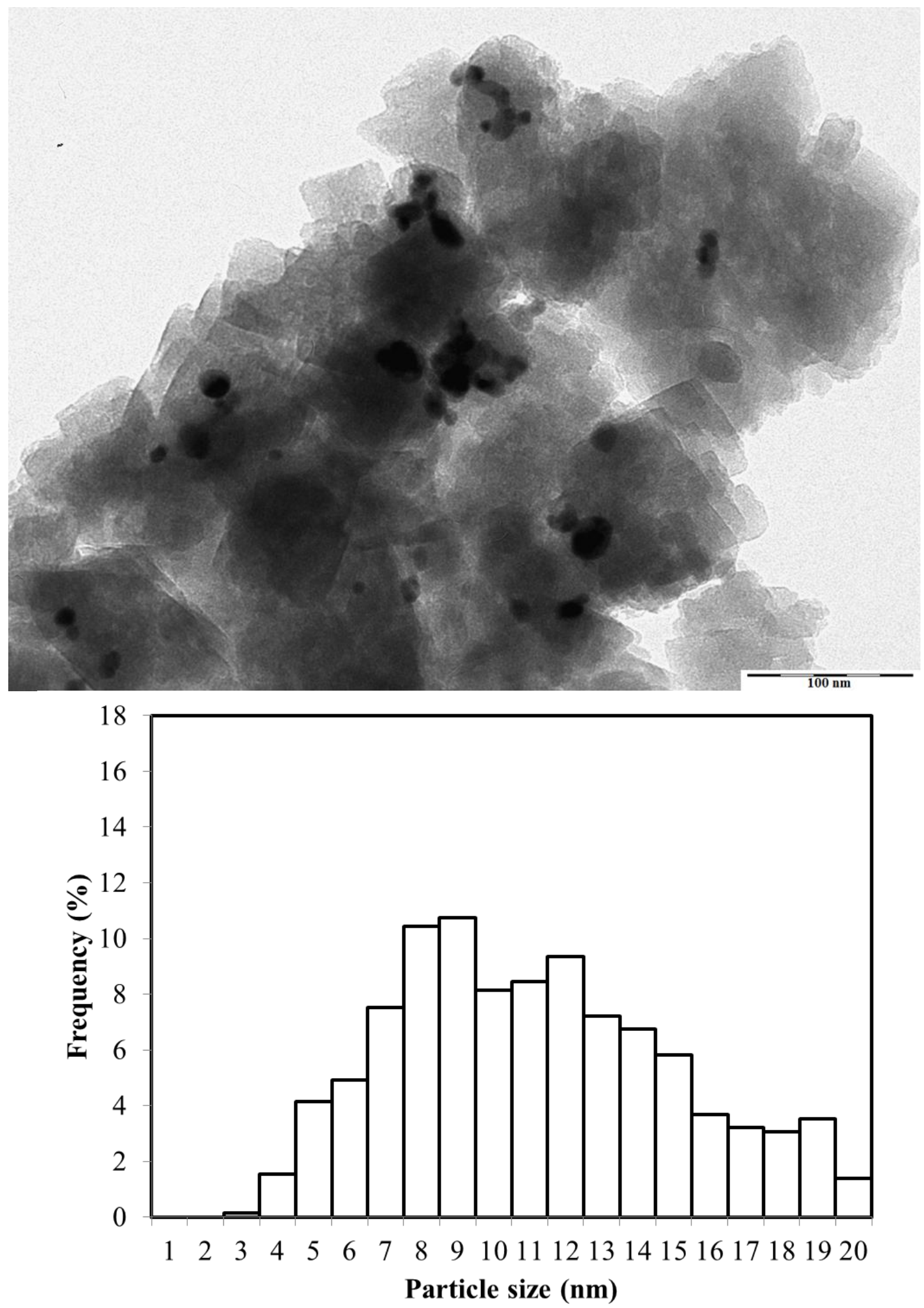

Fig. 10b 